\title{
Pensiones para personas con discapacidad en Colombia ${ }^{1}$
}

\author{
Pension System for People with Disabilities in Colombia
}

Recibido: 10 de mayo de 2017 - Revisado: 8 de noviembre de 2017 - Aceptado: 5 de diciembre de 2017

\section{Carlos Parra Dussan ${ }^{2}$}

\section{Resumen}

En Colombia, el derecho a la pensión, en cualquiera de sus modalidades, constituye uno de los mecanismos para garantizar el derecho a la seguridad social. Con el propósito de determinar cuáles regímenes pensionales se adecúan más a la realidad social y laboral de la población con discapacidad en el país, se revisaron la legislación y la jurisprudencia colombianas mediante un método de estudio exploratorio-descriptivo. Se encontró que ese derecho confiere un tratamiento especial para las personas con discapacidad. En la legislación colombiana se regulan con protección constitucional especial, cuanto menos, diez clases de pensiones para este grupo de personas.

\section{Palabras clave}

Acciones afirmativas, discapacidad, pensiones.

\begin{abstract}
In Colombia, the right to a pension, in any modality, is one of the mechanisms for guaranteeing the right to social security. In order to determine which pension regimes are more suited to the social and labor reality of the country's people with disabilities, Colombian legislation and jurisprudence were reviewed through an exploratorydescriptive study method. It was found that this right gives special treatment to that population. Colombian legislation regulates at least ten kinds of pensions for this group of people with special constitutional protection.
\end{abstract}

\section{Keywords}

Affirmative actions, disability, pensions.

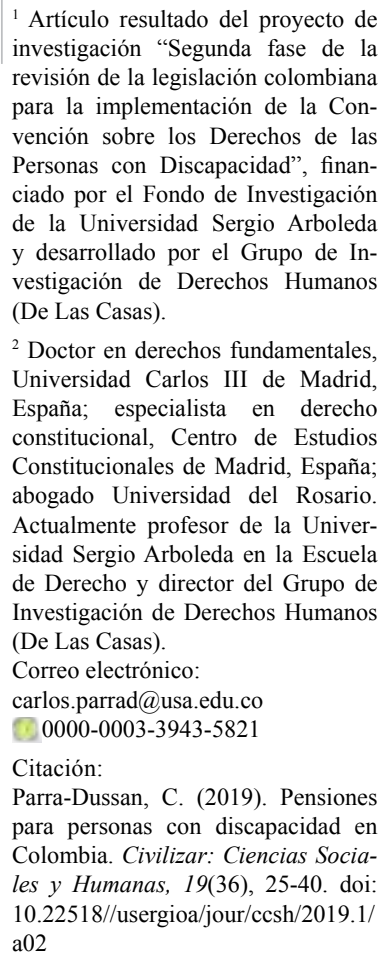

${ }^{1}$ Artículo resultado del proyecto de investigación "Segunda fase de la revisión de la legislación colombiana para la implementación de la Convención sobre los Derechos de las Personas con Discapacidad", financiado por el Fondo de Investigación de la Universidad Sergio Arboleda y desarrollado por el Grupo de Investigación de Derechos Humanos (De Las Casas).

${ }^{2}$ Doctor en derechos fundamentales, Universidad Carlos III de Madrid, España; especialista en derecho constitucional, Centro de Estudios Constitucionales de Madrid, España; abogado Universidad del Rosario. Actualmente profesor de la Universidad Sergio Arboleda en la Escuela de Derecho y director del Grupo de Investigación de Derechos Humanos (De Las Casas).

Correo electrónico: carlos.parrad@usa.edu.co

0000-0003-3943-5821

Citación:

Parra-Dussan, C. (2019). Pensiones para personas con discapacidad en Colombia. Civilizar: Ciencias Sociales y Humanas, 19(36), 25-40. doi 10.22518//usergioa/jour/ccsh/2019.1/ $\mathrm{a} 02$ 


\section{Introducción}

Este artículo analiza el régimen pensional en Colombia y la legislación sobre discapacidad, y busca adecuar las pensiones que más favorezcan a esta población, bien a través de acciones afirmativas o a través de propios beneficios pensionales por su condición de grupos de especial protección constitucional.

El problema de investigación parte del cuestionamiento sobre cuáles son los principales retos para la legislación colombiana en materia de discapacidad y específicamente en el tema pensional con la aprobación e implementación de la Convención sobre los Derechos de las Personas con Discapacidad como nuevo paradigma de protección.

El presente artículo se hizo con un método de estudio exploratorio - descriptivo; tiene un enfoque analítico y comparativo porque busca establecer las posibles soluciones en materia pensional para las personas con discapacidad, a partir de la normatividad actual. Está orientado a la obtención de información para establecer el impacto de la ratificación de la Convención sobre los Derechos de las Personas con Discapacidad, en materia pensional teniendo en cuenta que los estudios jurídicos sobre discapacidad son recientes en Colombia.

Ahora más que nunca es necesario elaborar un nuevo diseño institucional de la discapacidad en Colombia; de ajustar la legislación sobre seguridad social en pensiones de personas con discapacidad de acuerdo con los recientes desarrollos conceptuales nacionales e internacionales que regulan la política social, con el fin de avanzar en la garantía del goce efectivo de los derechos de esta población. Esa es la hipótesis de la investigación. Se debe profundizar sobre las posturas conceptuales que han orientado la legislación de la política social en Colombia, para entender por qué, en determinadas circunstancias, no se pueden abordar enfoques universales para atender las necesidades de grupos poblacionales que, por sus condiciones de exclusión social, están por fuera de los beneficios del desarrollo.

El derecho a la seguridad social aparece en la Carta Política, como un derecho irrenunciable; como un servicio público inherente a la finalidad social del Estado, el cual debe asegurar su prestación eficiente a todos los habitantes del territorio nacional con sujeción a los principios de eficiencia, universalidad y solidaridad (Constitución Política de Colombia, artículos $46,49$ y 365,1991$)$. Una de las expresiones del derecho a la seguridad social es el derecho a la pensión en sus distintas modalidades; hay una regulación especial para las personas con discapacidad, que en el ámbito laboral se trata de invalidez. La propia Constitución Política señala que las personas con discapacidad tienen debilidad manifiesta y, por lo tanto, el Estado Social de Derecho puede romper el principio de igualdad dando algunas ventajas en favor de esta población, en lo que se ha denominado acciones afirmativas (Constitución Política de Colombia, artículo 13, 1991).

\section{El derecho a la pensión}

La legislación colombiana establece acciones afirmativas al consagrar cuanto menos diez clases de pensiones especiales para personas con discapacidad: la pensión de invalidez, la de invalidez de jóvenes, la de invalidez de personas con discapacidad, la pensión de vejez con reducción de la edad por discapacidad, la pensión de padres con hijos con discapacidad, la pensión subsidiada, la pensión sustitutiva, la pensión de sobrevivientes, la pensión familiar de la Ley 1580 de 2012; incluso cabe mencionar la pensión de víctimas con discapacidad, consecuencia del conflicto. Sobre cada una de estas se presenta a continuación un apartado particular.

\section{Pensión de invalidez}

\section{Generalidades.}

La ley 100 de 1993 consagró la figura de la invalidez, en el caso de que un trabajador 
pierda por accidente común el $50 \%$ o más de su capacidad laboral. A su vez, la Ley 860 de 2003 modificó el artículo 39 de la Ley 100 de 1993 así:

Artículo 39. Requisitos para obtener la pensión de invalidez. Tendrá derecho a la pensión de invalidez el afiliado al sistema que conforme a lo dispuesto en el artículo anterior sea declarado inválido y acredite las siguientes condiciones.

1. Invalidez causada por enfermedad: Que haya cotizado cincuenta (50) semanas dentro de los últimos tres (3) años inmediatamente anteriores a la fecha de estructuración...

2. Invalidez causada por accidente: Que haya cotizado cincuenta (50) semanas dentro de los últimos tres (3) años inmediatamente anteriores al hecho causante de la misma...

(Congreso de Colombia, Ley 860, 2003).

Sabemos que el término invalidez es peyorativo, pues significa que no es válido, pero en este texto lo dejamos dado que la figura jurídica en el ámbito laboral lo establece así; se da la calificación de inválido no de discapacidad; además, la Corte Constitucional en la Sentencia C-458 de 2015, lo declaró exequible.

Como se observa, se deben cotizar al menos 50 semanas dentro de los últimos tres años, bien para adquirir la pensión por enfermedad o por accidente. De acuerdo con el artículo 38, para efectos del presente capítulo, se considera inválida la persona que por cualquier causa de origen no profesional, no provocada de forma intencional, hubiere perdido el $50 \%$ o más de su capacidad laboral.

\section{Pensión con el 50\% de invalidez.}

La Corte Constitucional en la Sentencia C-589 de 2012, declaró exequible la expresión "el 50\% o más de", contenida en el artículo 38 de la Ley 100 de 1993; también señaló que la norma censurada no excluye de la asistencia y protección necesarias a las personas con disca- pacidad inferior al $50 \%$ de pérdida de la capacidad laboral, pues ellas están en la posibilidad de continuar en el mercado laboral, al tiempo que se les reconoce el derecho a la dignidad y a la igualdad, por lo que gozan de todas las garantías que le son propias, como la estabilidad laboral reforzada, entre otros (Sentencia C-589, 2012).

En conclusión, las personas que no sean consideradas inválidas para laborar, no solo gozan de la capacidad para proveerse de los recursos necesarios, sino que se garantiza la integración social mediante el acceso efectivo al trabajo; así obtienen el disfrute de los servicios de salud y rehabilitación cuando sea posible.

\section{Pensión de invalidez para jóvenes}

La Ley 100 de 1993, agrega que "los menores de veinte (20) años de edad sólo deberán acreditar que han cotizado veintiséis (26) semanas en el último año inmediatamente anterior al hecho causante de su invalidez o su declaratoria" (Ley 100, artículo 39, parágrafo 1, 1993). Por su parte, la Corte Constitucional en la Sentencia C-020 de 2015, concluyó que el legislador vulneró el derecho de los jóvenes con veinte años de edad o más a disfrutar sin discriminaciones del servicio de seguridad social, de acuerdo con la Constitución Política artículos 13, 48 y 93. El argumento principal es que definió una regla especial de acceso a las pensiones de invalidez en virtud de la cual solo los menores de veinte años pueden acceder a estas sin necesidad de acreditar, como lo exigen las normas generales, 50 semanas en los tres años anteriores a la estructuración de invalidez, si se tienen 26 semanas en el año anterior a la estructuración o la declaración de ésta. Allí también concluyó que el artículo 39 de la Ley 100 de 1993 excluía, sin justificación suficiente, a un grupo poblacional joven que, al tener veinte años de edad o más, se encuentra en las mismas condiciones que los menores de veinte años. Por lo tanto, para remediar el déficit de protección, la Corte resolvió declarar exequible 
la norma acusada, con la condición de que lo allí está previsto en materia de pensiones de invalidez se extienda, en cuanto sea más favorable, a toda la población joven (Sentencia C-020, 2015).

\section{Pensión de invalidez para personas con discapacidad}

La pensión de invalidez puede generarse por enfermedades o accidentes de riesgo común o de origen profesional, aún en personas que ya tienen invalidez, como son las personas con discapacidad. Al respecto, la Corte Constitucional determinó:

Cuando una entidad estudia la solicitud de reconocimiento de una pensión de invalidez de una persona que tiene una enfermedad crónica, degenerativa o congénita, deberá establecer como fecha de estructuración de la invalidez el momento en que la persona haya perdido de forma definitiva y permanente su capacidad laboral igual o superior al 50\% y a partir de ésta verificar si la persona que ha solicitado la pensión de invalidez cumple con los requisitos establecidos por la normatividad aplicable para el caso concreto. (Sentencia T-483, 2014).

De forma previa, la misma Corte ya había tutelado los derechos a la seguridad social y a no ser discriminado, de una persona con discapacidad mental congénita, que solicitó su pensión de invalidez. La entidad demandada la negó, porque tuvo como fecha de estructuración su nacimiento (Sentencia T-427, 2012). Sobre esto, la Corte concluyó que:

Si se aceptara esta interpretación, se estaría admitiendo que a las personas que nacieron con discapacidad, por razón de su especial condición, no se les debe garantizar la posibilidad de procurarse por sus propios medios una calidad de vida acorde con la dignidad humana, ni la posibilidad de acceder a una pensión de invalidez, derechos que sí están reconocidos a las demás personas. (Sentencia T-483, 2014).
Así pues, se debe garantizar la posibilidad de alcanzar una digna calidad de vida a las personas que nacieron con discapacidad, mediante el acceso a una pensión de invalidez.

\section{Pensión de vejez para personas con discapacidad}

La legislación establece que para tener el derecho a la pensión de vejez, el afiliado debe haber cumplido 57 años de edad si es mujer y 62 si es hombre, así como haber cotizado un mínimo de mil semanas en cualquier tiempo. Sin embargo, quienes cumplan 55 años de edad, hayan cotizado en forma continua o discontinua 1000 o más semanas al régimen de seguridad social de la Ley 100 de 1993, y tengan invalidez del $50 \%$ o más, están exentas de estos requisitos.

Las personas con discapacidad tienen tres requisitos para pensionarse por vejez: el primero es tener una invalidez del $50 \%$ o más de acuerdo a la junta de calificación de invalidez. Segundo es que cumplan 55 años de edad, así se reduce en siete y cinco años la edad de pensión para hombres y mujeres respectivamente. El tercer requisito es que hayan cotizado en forma continua o discontinua 1000 o más semanas al régimen de seguridad social establecido en la Ley 100 de 1993, lo que reduce la obligación de cotizar en 300 semanas (Ley 797, artículo 9, parágrafo $\left.4^{\circ}, 2003\right)$.

Sin embargo, no tiene lógica jurídica que las personas con discapacidad se pensionen hasta los 55 años, mientras las madres o padres con hijos con discapacidad pueden pensionarse una vez cumplan las semanas de cotización que exige la ley, sin importar la edad.

\section{Pensión para padres con hijos con discapacidad}

La legislación prevé que las madres trabajadoras cuyo hijo padezca invalidez física o mental, debidamente calificada y hasta tanto 
permanezca en este estado y continúe dependiendo de la madre, tendrá derecho a recibir la pensión especial de vejez a cualquier edad, siempre que haya cotizado al Sistema General pensiones cuanto menos el mínimo de semanas exigido en el régimen de prima media (Ley 100, parágrafo 4, inciso 2, artículo 33 de la de 1993, modificado por Ley 797, artículo 9, 2003). A su vez, la Corte Constitucional declaró condicionalmente exequible la Ley 797 de 2003, en el sentido de que se hará extensivo al padre cabeza de familia de hijos discapacitados y que dependan de él en lo económico (Sentencia C-758, 2014).

Otro aspecto beneficioso de la norma, es que si la madre o padre ha fallecido y el otro padre tiene la patria potestad del menor inválido, podrá pensionarse con los requisitos y en las condiciones establecidas en este artículo. En este sentido, la Corte Constitucional declaró exequible, la expresión "siempre que haya cotizado al Sistema General de Pensiones cuando menos el mínimo de semanas exigido en el régimen de prima media para acceder a la pensión de vejez" (Sentencia C-758 de 2014).

En conclusión, la Corte consideró que todas las madres y padres que tengan hijos con discapacidad, tienen derecho a pensionarse a cualquier edad, siempre que hayan cotizado las semanas que exige la ley, tanto si están afiliados al Régimen Solidario de Prima Media con Prestación Definida, como como si lo están al Régimen de Ahorro Individual con Solidaridad (Sentencia C-758, 2014).

\section{Pensión subsidiada}

Se trata de una ampliación de la cobertura mediante un subsidio a las cotizaciones para pensiones de la población que, por condición socioeconómica, no tienen acceso a los sistemas de seguridad social. Surgió como un programa del Consorcio Prosperar, ahora Colombia Mayor, que nació con la Ley 100 de 1993 y la creación del Fondo de Solidaridad
Pensional, como una cuenta especial de la Nación desarrollada por las leyes 1151 de 2007 y 1187 de 2008, y reglamentada con el Decreto 4944 de 2009.

\section{Consorcio Prosperar.}

Es un programa que otorga un subsidio en los aportes para pensión de aquellas personas que no tienen la posibilidad de obtenerla en el sistema general. En la actualidad, lo administra Colpensiones (Administradora Colombiana de Pensiones). Este programa está dirigido a trabajadores asalariados y desempleados de la zona urbana y rural, como madres comunitarias, deportistas, concejales, artistas y personas con discapacidad. En el momento que una persona se integra a estos aportes mensuales obligatorios, está construyendo un futuro seguro con su propio capital para el día en que decida hacer un retiro de su vida laboral.

El Decreto que reglamenta el sistema dice que "la base del ingreso de cotización debe ser el $40 \%$ valor bruto, facturado en el contrato mensualmente" (Decreto 1703, artículo 23, 2002). Sin embargo, con base en el anterior artículo, Ley 1122, el sistema general de seguridad social de salud reglamenta que las personas en prestación de servicios que son contratistas independientes deben hacer cotizaciones al sistema general de seguridad social de salud de un valor del $40 \%$ como máximo del valor mensual estipulado en el contrato. Se entiende que los afiliados reciben esto para su beneficio personal y el $60 \%$ que resta, también se entiende que es para sus propios costos (Ley 1122, artículo 18, 2007).

Se deduce que el IVA también corresponde al $40 \%$ del valor mensual del contrato (para las personas que deben responder al impuesto). El $16 \%$ es para pensiones y el $12,5 \%$ es dirigido a salud (Los pensionados aportan para salud el $12 \%$ ). El ingreso base de cotización no puede ser mayor a 25 SMLMV, ni menor a 1 salario mínimo legal mensual "vigente" SMLMV. 
Hay muchos casos en que el ingreso de cotización base es igual o superior a 4 salarios mínimos "vigentes" y la obligación de hacer aportes al fondo de solidaridad pensional (Sistema General de Pensiones - Colpensiones). Los afiliados al Consorcio Prosperar deben ser cumplidos en todos los pagos (Decreto 1670, 2007).

\section{Consorcio Colombia Mayor.}

El Consorcio Colombia Mayor es una alianza estratégica entre sociedades fiduciarias del sector público: Fiduprevisora S.A., Fiducoldex S.A. y Fiducentral S.A., que tiene por objeto administrar los recursos del Fondo de Solidaridad Pensional, en virtud del contrato de fiducia pública No. 216 de 2013, suscrito con el Ministerio del Trabajo.

En su calidad de administrador fiduciario del Fondo de Solidaridad Pensional, el consorcio tiene a cargo las subcuentas de solidaridad y subsistencia, con las que financia el Programa de Subsidio al Aporte en Pensión y el Programa de Solidaridad con el Adulto Mayor, Colombia Mayor.

El Programa de Solidaridad con el Adulto Mayor (Colombia Mayor) busca aumentar la protección de los adultos mayores desamparados, que no cuentan con una pensión o que viven en la indigencia o en la extrema pobreza. Esto se hace por medio de un subsidio económico, a través del Ministerio del Trabajo. El Gobierno Nacional planea alcanzar la cobertura total de esta población vulnerable, lo que significa una vinculación cercana a los 2400000 adultos mayores en todo el territorio nacional, que cumplen con los requisitos para ingresar a este programa.

\section{Pensión familiar}

La pensión familiar fue creada por la Ley 1580 de 2012 y reglamentada por el Decreto 288 de 2014, para beneficiar aquellas personas que, a pesar de haber cotizado al régimen de pensión, no cumplen los requisitos para acceder a una pensión de vejez. La Corte determinó la constitucionalidad de dicha ley para distribuir de forma equitativa los subsidios estatales implícitos en la pensión familiar. Para ello dio prioridad a los cotizantes en mayor condición de vulnerabilidad socioeconómica, extendió progresivamente la cobertura del sistema y garantizó su sostenibilidad financiera (Sentencia C-613, 2013).

Posteriormente, la misma Corte declaró cosa juzgada constitucional, respecto del principio de igualdad en pensión familiar relacionada a los beneficiarios en régimen de prima media. Como requisitos comunes a los regímenes, encontramos que los cónyuges o compañeros permanentes deben estar afiliados al mismo régimen; en el caso de ahorro individual, al mismo fondo de pensiones y acreditar cinco años de convivencia permanente iniciada antes de los 55 años de edad.

En el caso del régimen de prima media, los cónyuges o compañeros permanentes deben cumplir los requisitos para obtener una indemnización sustitutiva, tener la edad mínima de pensión, declarar la imposibilidad de seguir cotizando y no tener reconocida ninguna otra prestación; sumar entre los dos el número mínimo de semanas para obtener la pensión de vejez; estar clasificados en el nivel 1 o 2 del Sisbén y haber cotizado $25 \%$ de las semanas requeridas al momento de tener 45 años. Para ahorro individual, las dos personas deben cumplir los requisitos para la devolución de saldos: edad mínima de pensión y tener entre los dos el capital mínimo necesario de acuerdo con la norma vigente para tener la garantía de pensión mínima. En cualquier régimen, la clasificación en el Sisbén debe estar vigente al momento de cumplir la edad de pensión. (Sentencia C-913, 2013).

La normatividad impuso cargas adicionales como la prueba de la convivencia: no basta el registro civil de matrimonio o la declaración 
de la unión marital de hecho, debe adicionarse una declaración extra juicio de un testigo que reafirme convivencia y el tiempo. Estableció el número de semanas que se debieron haber cotizado: si cumplió los 45 años en el 2004 o antes debió haber tenido 250 semanas cotizadas; si los cumple en este año 2014, debe tener 318,75 semanas, si los cumple en el 2015 o después debe tener 325 semanas (Decreto 288, 2014).

También se estableció un procedimiento para cambio de régimen o de fondo de pensiones, en caso de ser necesario. Respecto a la titularidad de la pensión, en el caso del régimen de prima media será el cónyuge o compañero permanente que tenga más semanas cotizadas y para el caso del ahorro individual, el que cuente con mayor saldo en su cuenta de ahorro individual. En el caso que los cónyuges o compañeros permanentes estén en distinto régimen de pensiones, se debe trasladar el cónyuge que no tenga la condición de titular. Con esta regulación, el traslado se podrá en cualquier momento, siempre y cuando sea para obtener la pensión familiar (Decreto 288, 2014).

La normatividad contempla que la pensión familiar es una sola e incompatible con cualquier otro tipo de pensión, en caso de fallecimiento del beneficiado, el $50 \%$ correspondiente a la persona fallecida pasa a sus hijos menores si los hubiere, si no, incrementa la cuota del cónyuge supérstite. En caso de separación o divorcio, la figura de pensión familiar se extinguirá y cada uno recibirá $50 \%$ (Decreto 288, 2014). Por su parte, la Corte Constitucional explica que:

La aplicación del principio de progresividad y el cumplimiento de los deberes de protección del contenido mínimo esencial y fuerte restricción a las medidas de retroceso, solucionan en gran parte el debate sobre la eficacia del principio de universalidad de los derechos sociales prestacionales en sociedades que, como la colombiana, se encuentran en un entorno de recursos económicos escasos. (Sentencia T-441, 2006).
En conclusión, la pensión familiar brinda la posibilidad de sumar los aportes a pensión con su cónyuge o compañero permanente, para tener acceso a una pensión que les permita llevar una vida digna.

\section{Pensión sustitutiva}

La Corte Constitucional aclaró que:

La sustitución pensional, se materializa cuando, el afiliado ya ostenta la condición de pensionado o cumple los requisitos legalmente exigibles para el efecto, de forma que esta no consagra un nuevo derecho del que son titulares los familiares del pensionado, sino que transfiere o sustituye aquel del que éste goza. (Sentencia T-564 de 2015).

Una de las expresiones del derecho a la seguridad social es el derecho a la pensión en sus distintas modalidades, una de ellas es la sustitución pensional. Consiste en la garantía que le asiste al grupo familiar de una persona pensionada por vejez o invalidez, o de un afiliado al Sistema General de Seguridad Social en Pensiones que fallece de reclamar la prestación que se había generado a favor del causante, para enfrentar el posible desamparo al que se puedan someter por el deceso de la persona de la cual dependían en lo económico (Ley 100, artículo 46, 1993).

La sustitución pensional es un derecho que permite a una o varias personas entrar a gozar de los beneficios de una prestación económica antes percibida por otra, lo cual no significa el reconocimiento del derecho a la pensión sino la legitimación para reemplazar a la persona que venía gozando de este derecho. (Sentencia T- 431, 2011).

En suma, lo que se busca con la sustitución pensional es que los familiares del pensionado o afiliado muerto puedan reemplazar el sustento económico que este les proporcionaba y que su muerte no deteriore sus condiciones de vida. Por esta razón, la Corte ha resaltado que el 
reconocimiento de esta prestación constituye un derecho fundamental por su estrecha relación con la garantía del mínimo vital.

\section{La pensión sustitutiva no puede desconocer al hijo inválido.}

La Corte Constitucional revisó el caso de una demandante que solicitaba la sustitución pensional a la entidad demandada, puesto que, al morir su padre, otorgó la sustitución pensional únicamente a favor de su madre, a pesar de que la demandada ya presentaba pérdida del $70 \%$ de la capacidad laboral a causa de un síndrome mental orgánico crónico. Tras la muerte de la madre, la tutelante alega estar en desamparo pues sus hermanos no cuentan con recursos económicos para ayudarla, razón por la cual solicitó que le fuera sustituida la pensión (Sentencia T-378, 1997).

A través de La Sentencia, la Corte Constitucional resolvió conceder la tutela a la demandante y reconocer y sustituirle el derecho a la pensión mensual vitalicia de jubilación. Esta acción, sustentada en que al tratarse de una persona con incapacidad total, tiene el derecho a la sustitución pensional y a los derechos conexos ya que estos no prescriben.

\section{Matrimonio de persona inválida no impide pensión.}

Dentro de los beneficiarios de la sustitución pensional se encuentran los descendientes del causante, quienes tendrán derecho cuando sean hijos inválidos quienes, en lo económico, dependían del causante (Ley 797, artículo 13, literal c, 2003). La Corte Constitucional determinó que las nupcias de un hijo en situación de discapacidad no eliminan el derecho al reconocimiento de la sustitución pensional por dos argumentos. El primero, porque no existe norma legal que contemple la extinción del derecho prestacional. El segundo, porque la libre decisión de conformar familia no necesariamente implica una capacidad económica determinada (Sentencia T-109 de 2016).
En análogo sentido, la Corte Constitucional analizó la constitucionalidad de una serie de normas que establecían la pérdida de la pensión de sobrevivientes para la viuda por el hecho de contraer nuevas nupcias. La conclusión siempre fue que esta medida vulneraba la Constitución (Sentencia C-309, 1996; Sentencia C-653, 1997; Sentencia C-182, 1997).

\section{Pensión de sobreviviente}

La Corte Constitucional hizo la distinción entre la pensión de sobreviviente y la pensión sustitutiva:

A pesar de que la legislación vigente no prevé distinción alguna en su consagración, la pensión de sobrevivientes se diferencia de la figura denominada sustitución pensional, en el hecho de que si bien ambas comparten, desde un punto de vista teleológico, una misma finalidad, cubren contingencias o situaciones de hecho diferente. (Sentencia T-564, 2015).

La pensión de sobrevivientes se configura en los eventos en los que un trabajador, sin tener la condición de pensionado ni cumplir con los requisitos legales para hacerlo, fallece $\mathrm{y}$ asegura que su núcleo familiar no se vea irrazonablemente afectado por dicha situación, previa verificación del cumplimiento de determinados requisitos creados por la ley (Sentencia T-564, 2015).

Según la Corte Constitucional, el carácter de fundamental del derecho a la sustitución pensional, no solo deriva del hecho de estar relacionado con el mínimo vital, sino también de que sus beneficiarios sean sujetos de especial protección constitucional, como adultos mayores, niños y personas con discapacidad (Sentencia T- 662 de 2010). En esa oportunidad se revisó el caso de un joven que solicitó la pensión de sobrevivientes por la muerte de su padre, solicitud que le fue negada por la entidad demandada, en virtud del artículo 47 de la Ley 100 de 1993. Sin embargo, la Corte se refirió a los requisitos establecidos en dicha norma en los siguientes términos: 
De lo anterior se infiere, y en especial para el caso de los hijos inválidos, que para poder obtener el reconocimiento de la pensión de sobrevivientes es necesario acreditar el cumplimiento de los siguientes requisitos: (i) el parentesco, (ii) el estado de invalidez del solicitante, y (iii) la dependencia económica respecto del causante. (Sentencia T-674, 2010).

Según el artículo 14 del Decreto 1889 de 1994, el estado de invalidez de los posibles beneficiarios de la pensión de sobrevivientes se determina conforme a lo previsto por el Decreto 1346 del mismo año, el cual fue derogado por el Decreto 2463 de 2001. Este último consagra que el porcentaje de la pérdida de la capacidad laboral y la fecha de estructuración de la invalidez deben ser calificadas, en primera instancia, por las Juntas Regionales de Calificación de Invalidez $y$, en segunda instancia, por la Junta $\mathrm{Na}-$ cional de Calificación de Invalidez. Sin embargo, al respecto se pronunció la Corte y dijo que:

El porcentaje de la pérdida de la capacidad laboral y la fecha de estructuración de la invalidez debe ser calificada en principio por la entidad encargada de reconocer la prestación económica; este dictamen podrá ser objeto de los recursos de reposición y apelación respectivamente, ante la Junta Regional y Nacional de Calificación de invalidez. Dichas juntas son las encargadas de dirimir los conflictos que se presentan entre la evaluación que de su propia invalidez realiza quien pretende la pensión y aquella valorada por la entidad llamada al pago de las correspondientes mesadas [AFP, ARP, Aseguradoras o el ISS] (Sentencia T-662, 2010).

El requisito del parentesco que debe existir entre el beneficiario de la pensión de sobrevivientes y el causante se prueba con el certificado del registro civil de nacimiento (Decreto 1889, artículo 13, 1994). El cumplimiento del requisito de dependencia económica se determina cuando la subsistencia del beneficiario deriva del causante (Decreto 1889, artículo 16, 1994). Dicha dependencia "debe estar presente al momento de la muerte del causante, y la continuidad del pago de la prestación está sujeta a que persistan las situaciones anotadas; de lo contrario, se extingue el derecho a la pensión de sobrevivientes" (Sentencia T-662, 2010).

Sin embargo, la Corte Constitucional declaró la inconstitucionalidad de la expresión "esto es, que no tienen ingresos adicionales", contenida en el literal c del artículo 13, de la Ley 797 del año 2003, que establece los beneficiarios de la pensión de sobrevivientes, pues en el caso de los hijos con discapacidad se establecía un requisito adicional y diferencial para acceder a esta prestación. De esta manera, la Corte Constitucional en la Sentencia C-066 de 2016, declaró inexequible la expresión que alude a dichos ingresos adicionales, de manera que bastará acreditar la situación de discapacidad para tener derecho a la pensión de sobrevivientes. Esto quiere decir que las personas con discapacidad tienen dos requisitos para tener derecho a la pensión como sobrevivientes de sus padres, el primero es acreditar la situación de discapacidad y el segundo es demostrar el parentesco. En estos casos, la Corte ha considerado que se debe amparar el derecho a la seguridad social de las personas inválidas, mediante el reconocimiento y orden de pago de la sustitución pensional y/o pensión de sobrevivientes (Sentencia C-066, 2016).

\section{Pensión para hijos de crianza}

La Corte Constitucional concedió al menor menor Yocimar Stiben Camargo el derecho a que se le reconozca y se le pague la pensión de sobrevivientes de su abuelo, el señor Luis María Camargo, y reivindicó la condición de hijo de crianza del causante. La Corte determinó que se vulneraron los derechos fundamentales de un menor en situación de discapacidad, por la negativa de un fondo de pensiones de reconocer y negarse a pagar la pensión de sobreviviente solicitada por su padre biológico, Miguel Antonio Camargo de 51 años (Sentencia T-074 de 2016). 
Él aducía que el menor era hijo de crianza del causante, es decir, el abuelo, dado que no tenía la posibilidad de responder en el aspecto económico por su hijo biológico. La Corte falló a favor de Miguel Antonio, en nombre del niño, contra el Fondo de Pensiones Económicas, Cesantías y Pensiones-Foncep, por dos motivos. Fue el señor Luis María quien se hizo cargo del menor desde el 2006 hasta el 29 de diciembre de 2015, fecha en la que murió. Por otro lado, el menor tiene autismo. El caso es típico en Colombia, por la difícil situación económica de la familia (Sentencia T-074 de 2016).

Como conclusiones frente a este caso, la Corte Constitucional determinó que los hijos de crianza por asunción solidaria de la paternidad son beneficiarios de la pensión de sobrevivientes, ya que el derecho debe ajustarse a las realidades jurídicas reconociendo y brindando protección a aquellas relaciones donde las personas no se encuentran unidas por vínculos jurídicos o naturales. Por otro lado, con esta Sentencia el caso más frecuente será que los nietos menores de edad podrán heredar la pensión de sobreviviente de sus abuelos, siempre y cuando ellos hayan ejercido como padres de crianza (Sentencia T-074 de 2016).

\section{Pensión para las víctimas con discapacidad}

No es una pensión contributiva. En estricto sentido es una prestación humanitaria para víctimas del conflicto armado, creada por el artículo 45 de la Ley 104 de 1993, y modificada y prorrogada por la Ley 241 de 1995, que exigía un $50 \%$ de pérdida de capacidad laboral en razón de dicho conflicto. La Corte Constitucional la reconoció como derecho para las víctimas con discapacidad, y consiste en un salario mínimo para quienes perdieron su capacidad laboral y no tienen otra alternativa pensional (Sentencia C-767 de 2014).

En este sentido, la Corte Constitucional declaró exequibles los artículos $1^{\circ}$ de la Ley
1106 de 2006 y $^{\circ}$ de la Ley 1421 de 2010 , en el entendido que:

Las víctimas del conflicto armado interno, que sufrieron una pérdida del $50 \%$ o más de su capacidad laboral calificada con base en el Manual Único para la calificación de invalidez, tendrán derecho a una pensión mínima legal vigente, de acuerdo con lo contemplado en el Régimen General de Pensiones de la Ley 100 de 1993, siempre y cuando carezcan de otras posibilidades pensionales y de atención en salud. (Sentencia C-767 de 2014).

La Corte Constitucional también estudió si la omisión del legislador de los artículos $1^{\circ}$ de la Ley 1106 de 2006 y $1^{\circ}$ de la Ley 1421 de 2010, al abstenerse de prorrogar la vigencia de la pensión para las víctimas del conflicto armado con discapacidad y sin otra alternativa pensional, regulada originalmente en el artículo 46 de la Ley 418 de 1997, desconocía el principio de progresividad en materia de derechos económicos, sociales y culturales; los deberes sociales del Estado y la garantía de la igualdad material (Sentencia C-767, 2014).

Como se explica aquí, a partir de la promulgación de la Ley 1106 de 2006 y posteriormente con la Ley 1421 de 2010, se presentaba la pérdida de vigencia de la pensión para personas víctimas del conflicto, que cumplieran las condiciones consagradas en la Ley. Esta situación, sin duda, dejaba sin protección a una población que tenía una doble condición de vulnerabilidad, la de víctima del conflicto y la de persona con discapacidad.

La Corte realizó un análisis de esta prestación, que técnicamente no es una pensión contributiva para víctimas del conflicto armado que fue creada por el artículo 45 de la Ley 104 de 1993, modificada y prorrogada por la Ley 241 de 1995, que exigía un 50\% de pérdida de capacidad laboral en razón de dicho conflicto. 
Posteriormente, la Ley 418 de 1997 derogó de manera expresa la Ley 104 de 1993, luego ésta fue derogada por las leyes 1106 de 2006 y 1421 de 2010 sin contemplar esta pensión para víctimas con discapacidad, pero afortunadamente la Corte Constitucional prorrogó la vigencia de esta prestación económica (Sentencia C-767, 2014). Consideró que la creación de esta prestación a favor de las víctimas del conflicto armado y la posterior prórroga de las normas que la contienen, seguida de la exclusión que se acaba de mencionar, generaron un vacío normativo, al dejar fuera del ordenamiento jurídico el reconocimiento de esta prestación a víctimas del conflicto armado. Para la Corte:

La conducta omisiva del legislador implicó una trasgresión a la prohibición de regresividad de los derechos económicos, sociales y culturales, por cuanto las personas que han perdido su capacidad laboral en razón del conflicto armado y que no tienen otra alternativa para acceder a la pensión, fueron desprotegidas de forma abrupta y les fue recortada, sin justificación alguna, una prestación económica que les permitía hacer frente a sus necesidades básicas. (Sentencia C-767, 2014).

La Corte también consideró que no hay transgresión de lo ordenado por el Acto Legislativo 1 de 2005, por cuanto la prestación para las víctimas con discapacidad no está en el Régimen General de Pensiones, sino en el marco de los derechos humanos y de los deberes constitucionales del Estado colombiano. Por esta razón como señala que la prestación para las víctimas con discapacidad como consecuencia del conflicto armado "es de naturaleza especial, fundamentada en una situación generalizada de violencia, con efectos tangibles, reales, actuales y cuantificables, producto del conflicto armado interno" (Sentencia C-767, 2014).

En conclusión, la Corte Constitucional reconoció la vigencia de la prestación económica en favor de las víctimas con discapacidad como consecuencia del conflicto armado.
Con ello amplió progresivamente la garantía de sus derechos económicos, sociales y culturales, y cumplió con los deberes impuestos por el Estado Social de Derecho y el artículo 13 de la Constitución (Sentencia C-767, 2014).

\section{Conclusiones}

Las personas con discapacidad se pueden beneficiar de la pensión subsidiada, que es una ampliación de la cobertura mediante un subsidio a las cotizaciones para pensiones de la población que por su condición socioeconómica no tienen acceso a los sistemas de seguridad social, que surgió como un programa del Consorcio Prosperar, ahora Colombia Mayor, que nació con la Ley 100 de 1993 con la creación del Fondo de Solidaridad Pensional como una cuenta especial de la Nación, desarrollada por las leyes 1151 de 2007 y 1187 de 2008, reglamentada con el Decreto 4944 de 2009.

Para poder obtener el reconocimiento de la pensión de sobrevivientes es necesario acreditar el parentesco y el estado de invalidez del solicitante. Para efectos de determinar quién es inválido, el artículo 38 de la Ley 100 de 1993 estipula que es la persona que hubiere perdido el $50 \%$ o más de sus capacidades laborales por cualquier causa de origen no profesional.

Afortunadamente, la Corte Constitucional en la Sentencia C-066 de 2016, declaró inexequible la expresión que aludía a ingresos adicionales, de manera que bastará acreditar la situación de discapacidad para tener derecho a la pensión de sobrevivientes.

La Corte Constitucional en la Sentencia T-564 de 2015, aclaró que la sustitución pensional, se materializa cuando, el afiliado ya ostenta la condición de pensionado o cumple los requisitos legalmente exigibles para el efecto, de forma que esta no consagra un nuevo derecho del que son titulares los familiares del pensionado, sino que transfiere o sustituye aquel del que éste goza. 
Las personas con discapacidad tienen tres requisitos para pensionarse por vejez: el primero es tener una invalidez del $50 \%$ o más, el segundo es que cumplan 55 años de edad $\mathrm{y}$ el tercero es que hayan cotizado en forma continua o discontinua 1000 o más semanas al régimen de seguridad social establecido en la Ley 100 de 1993.

Todas las madres y padres que tengan hijos con discapacidad, tienen derecho a pensionarse a cualquier edad, siempre que hayan cotizado las semanas que exige la ley, independientemente del régimen pensional al que se encuentren afiliados.

Por su parte, la pensión familiar brinda la posibilidad de sumar los aportes a pensión con su cónyuge o compañero permanente, para tener acceso a una pensión que les permita llevar una vida digna.

Por último, la Corte Constitucional en la Sentencia C-767 de 2014, reconoció el derecho a una pensión para las víctimas con discapacidad, consistente en un salario mínimo para las víctimas del conflicto armado, que perdieron su capacidad laboral y no tienen otra alternativa pensional, con lo que aclara que no es una pensión, sino una ayuda del Estado en sentido estricto.

\section{Referencias}

Congreso de la República (1993). Por la cual se crea el sistema de seguridad social integral y se dictan otras disposiciones, Ley 100, Diario oficial No. 41.148, Colombia.

Congreso de la República (1993). Por la cual se consagran unos instrumentos para la búsqueda de la convivencia, la eficacia de la justicia y se dictan otras disposiciones, Ley 104, Diario oficial No. 41.158, Colombia.

Congreso de la República (1995). Por la cual se prorroga la vigencia, se modifica y adiciona la Ley 104 de 1993, Ley 241, Diario oficial No. 42.719, Colombia.

Congreso de la República (1997). Por la cual se consagran unos instrumentos para la búsqueda de la convivencia, la eficacia de la justicia y se dictan otras disposiciones. Ley 418, Diario oficial No. 43.201, Colombia.

Congreso de la República (2003). Por la cual se reforman algunas disposiciones del sistema general de pensiones previsto en la Ley 100 de 1993 y se adoptan disposiciones sobre los Regímenes Pensionales exceptuados y especiales, Ley 797, Diario oficial No. 45.079, Colombia.

Congreso de la República (2003). Por la cual se reforman algunas disposiciones del Sistema General de Pensiones previsto en la Ley 100 de 1993 y se dictan otras disposiciones, Ley 860, Diario oficial No. 45.415, Colombia.

Congreso de la República (2006). Por medio de la cual se prorroga la vigencia de la Ley 418 de 1997 prorrogada y modificada por las Leyes 548 de 1999 y 782 de 2002 y se modifican algunas de sus disposiciones, Ley 1106, Diario oficial No. 46.490, Colombia.

Congreso de la República (2007). Por la cual se expide el Plan Nacional de Desarrollo 2006-2010, Ley 1151, Diario oficial No. 46.700, Colombia.

Congreso de la República (2007). Por la cual se hacen algunas modificaciones en el Sistema General de Seguridad Social en Salud y se dictan otras disposiciones, Ley 1122 , Diario oficial No. 46.506, Colombia.

Congreso de la República (2008). Por la cual se adiciona un parágrafo 2 al artículo 2 de la Ley 1023 de 2006 y se dictan otras disposiciones, Ley 1187, Diario oficial No. 46.960, Colombia. 
Congreso de la República (2010). Por medio de la cual se prorroga la Ley 418 de 1997, prorrogada y modificada por las Leyes 548 de 1999, 782 de 2002 y 1106 de 2006, Ley 1421, Diario oficial No. 47.930, Colombia.

Congreso de la República (2012). Por la cual se crea la pensión familiar, Ley 1580, Diario oficial No. 48.570, Colombia.

Constitución Política de Colombia (1991). Corte Constitucional - Consejo Superior de la Judicatura.

Congreso de la República. Acto Legislativo 1 de 2005. Por el cual se adiciona el artículo 48 de la Constitución Política, (Diario oficial No. 45.980. Colombia).

Corte Constitucional (1996) Sentencia C-309, Magistrado Ponente: Eduardo Cifuentes Muñoz.

Corte Constitucional (1997) Sentencia C-653, Magistrado Ponente: José Gregorio Hernández Galindo.

Corte Constitucional (1997) Sentencia C-182, Magistrado Ponente: Hernando Herrera Vergara.

Corte Constitucional (1997) Sentencia T-378, Magistrado Ponente: Eduardo Cifuentes Muñoz.

Corte Constitucional (1999) Sentencia C- 080, Magistrado Ponente: Alejandro Martínez Caballero.

Corte Constitucional (1999) Sentencia C-870, Magistrado Ponente: Alejandro Martínez Caballero.

Corte Constitucional (2002) Sentencia C-130, Magistrado Ponente: Jaime Araujo Rentería.

Corte Constitucional (2006) Sentencia C-989, Magistrado Ponente: Álvaro Tafur Galvis.
Corte Constitucional (2006) Sentencia T-441, Magistrado Ponente: Jaime Córdoba Triviño.

Corte Constitucional (2006) Sentencia T- 692, Magistrado Ponente: Jaime Córdoba Triviño.

Corte Constitucional (2007) Sentencia T-236, Magistrado Ponente: Manuel José Cepeda Espinosa.

Corte Constitucional (2009) Sentencia T-777, Magistrado Ponente: Jorge Iván Palacio Palacio.

Corte Constitucional (2010) Sentencia T-049, Magistrado Ponente: Gabriel Eduardo Mendoza Martelo.

Corte Constitucional (2010) Sentencia T-561, Magistrado Ponente: Nilson Pinilla Pinilla.

Corte Constitucional (2010) Sentencia T-662, Magistrado Ponente: Jorge Iván Palacio Palacio.

Corte Constitucional (2010) Sentencia T-839, Magistrado Ponente: Jorge Ignacio Pretelt Chaljub.

Corte Constitucional (2010) Sentencia T-674, Magistrado Ponente: Jorge Ignacio Pretelt Chaljub.

Corte Constitucional (2011) Sentencia T-671, Magistrado Ponente: Humberto Antonio Sierra Porto.

Corte Constitucional (2011) Sentencia T-431, Magistrado Ponente: Jorge Ignacio Pretelt Chaljub.

Corte Constitucional (2012) Sentencia T-427, Magistrado Ponente: María Victoria Calle Correa.

Corte Constitucional (2012) Sentencia C-589, Magistrado Ponente: Nilson Pinilla Pinilla. 
Corte Constitucional (2012) Sentencia T-506, Magistrado Ponente: Jorge Iván Palacio Palacio.

Corte Constitucional (2013) sentencia T-022, Magistrado Ponente: María Victoria Calle Correa.

Corte Constitucional (2013) Sentencia C-613, Magistrado Ponente: Jorge Ignacio Pretelt Chaljub.

Corte Constitucional (2013) Sentencia T-819, Magistrado Ponente: Mauricio González Cuervo.

Corte Constitucional (2013) Sentencia C-913, Magistrado Ponente: Nilson Pinilla Pinilla.

Corte Constitucional (2013) Sentencia T-832a, Magistrado Ponente: Luis Ernesto Vargas Silva.

Corte Constitucional (2014) Sentencia T-443, Magistrado Ponente: María Victoria Calle Correa.

Corte Constitucional (2014) Sentencia T-483, Magistrado Ponente: María Victoria Calle Correa.

Corte Constitucional (2014) Sentencia T-580, Magistrado Ponente: Gloria Stella Ortiz Delgado.

Corte Constitucional (2014) Sentencia C-758, Magistrado Ponente: Martha Victoria Sáchica Méndez.

Corte Constitucional (2014) Sentencia C-767, Magistrado Ponente: Jorge Ignacio Pretelt Chaljub.

Corte Constitucional (2015) Sentencia C-020, Magistrado Ponente: María Victoria Calle Correa.

Corte Constitucional (2015) Sentencia T-564, Magistrado Ponente: Alberto Rojas Ríos.
Corte Constitucional (2015) Sentencia C-458, Magistrado Ponente: Gloria Stella Ortiz Delgado.

Corte Constitucional (2016) Sentencia C-066, Magistrado Ponente: Alejandro Linares Cantillo.

Corte Constitucional (2016) Sentencia T-109, Magistrado Ponente: Luis Guillermo Guerrero Pérez.

Corte Constitucional (2016) Sentencia T-074, Magistrado Ponente: Alberto Rojas Ríos.

Gobierno Nacional (1984). Por medio del cual se aprobó el reglamento del ISS, Decreto 232, Diario Oficial No 38.207. Colombia.

Gobierno Nacional (1990). Por el cual se aprueba el acuerdo número 049 de febrero 1 de 1990 emanado del Consejo Nacional de Seguros Sociales Obligatorios, Acuerdo 049, Diario Oficial No 39.303. Colombia.

Gobierno Nacional (1990). Por la cual se reforma el Estatuto de personal de Oficiales y Suboficiales de la Policía Nacional, Decreto 1212, Diario oficial No. 39.406. Colombia.

Gobierno Nacional (1990). Por el cual se reforma el estatuto del personal de agentes de la Policía Nacional, Decreto 1213, Diario oficial No. 39.406. Colombia.

Gobierno Nacional (1994). Por el cual se reglamenta parcialmente la Ley 100 de 1993. Decreto 1889, Diario oficial No. 41.480. Colombia.

Gobierno Nacional (1994). Por el cual se reglamenta la integración, la financiación y el funcionamiento de las Juntas de Calificación de Invalidez. Decreto 1346, Diario oficial No. 41.415. Colombia.

Gobierno Nacional (1995). Por el cual se adopta el Manual Único para la Calificación de la Invalidez. Decreto 692, Diario oficial No. 41.826. Colombia. 
Gobierno Nacional (1999). Por el cual se modifica el Decreto 692 de 1995. Decreto 917, Diario oficial No. 43.601. Colombia.

Gobierno Nacional (2001). Por el cual se reglamenta la integración, financiación y funcionamiento de las juntas de calificación de invalidez. Decreto 2463, Diario oficial No. 44.652. Colombia.

Gobierno Nacional (2002). Por el cual se adoptan medidas para promover y controlar la afiliación y el pago de aportes en el Sistema General de Seguridad Social en Salud. Decreto 1703, Diario oficial No. 44.893. Colombia.
Gobierno Nacional (2007). Por medio del cual se ajustan las fechas para el pago de aportes al Sistema de la Protección Social y para la obligatoriedad del uso de la Planilla Integrada de Liquidación de Aportes. Decreto 1670, Diario oficial No. 46.628. Colombia.

Gobierno Nacional (2009). Por el cual se modifica parcialmente el Decreto 3771 de 2007. Decreto 4944, Diario oficial No. 47.567. Colombia.

Gobierno Nacional (2014). Por el cual se reglamenta la Ley 1580 de 2012, Decreto 288, Diario oficial No. 49.062. Colombia. 
